\title{
An Insight into the Surface of Dental Implants
}

\author{
${ }^{1}$ Hina Kausher, ${ }^{2}$ Narendra Padiyar, ${ }^{3}$ Pragati Kaurani, ${ }^{4}$ Sudhir Meena, ${ }^{5}$ Devendra PS Chonkkar
}

\begin{abstract}
Osseointegration, the direct contact between living bone and the surface of load-carrying implant, is imperative for the long-term success of dental implants. There is no distinct relationship between osseointegration and defined surface characteristics, since a great number of different surfaces achieve osseointegration. However, the rate, extent, and the strength of this connection may be dependent on the surface characteristics of the implant. The aim of this article was to review the literature on the various approaches available to modify the bone-implant interface.
\end{abstract}

Keywords: Dental implant, Surface modifications, Topography.

How to cite this article: Kausher $\mathrm{H}$, Padiyar $\mathrm{N}$, Kaurani $\mathrm{P}$, Meena S, Chonkkar DPS. An Insight into the Surface of Dental Implants. J Mahatma Gandhi Univ Med Sci Tech 2017;2(1):23-28.

Source of support: Nil

Conflict of interest: None

\section{INTRODUCTION}

Beginning in the late 1960s, the focused efforts of Per Ingvar Branemark led to the detailed microscopic characterization of interfacial bone formation at machined titanium endosseous implants. ${ }^{1,2}$

Osseointegration, the direct contact between living bone and the surface of load-carrying implant, is imperative for the long-term success of dental implants. There is no distinct relationship between osseointegration and defined surface characteristics, since a great number of different surfaces achieve osseointegration. However, the stronger or weaker bone responses may be related to the surface phenomenon. ${ }^{3}$

According to Albrektsson and Sennerby, ${ }^{4}$ the following six parameters are prerequisite for establishing reliable osseointegration: Implant material, implant design, surface quality, bone status, surgical technique, and loading conditions. Implant surface character is one

\footnotetext{
${ }^{1}$ Postgraduate Student, ${ }^{2} \mathrm{Head},{ }^{3}$ Professor, ${ }^{4,5}$ Reader

${ }^{1-5}$ Department of Prosthodontics and Crown and Bridge Mahatma Gandhi Dental College \& Hospital, Jaipur, Rajasthan India

Corresponding Author: Hina Kausher, A-95, Opposite Greenland School, Raghunathpuri, Jhotwara, Jaipur, Rajasthan India, Phone: +918824190688, e-mail: hinaparihar22@ gmail.com
}

implant design factor that strongly influences the rate and extent of osseointegration. ${ }^{5}$

Dental implant quality depends on the chemical, physical, mechanical, and topographic characteristics of the surface. ${ }^{6}$

\section{BONE-IMPLANT INTERFACE MODIFICATION}

Various approaches have been suggested to obtain appropriate outcome at the bone-implant interface. As a general rule, an ideal implant biomaterial should present a surface that will not disrupt, and that may even enhance, the general processes of bone healing, regardless of implantation site, bone quantity, and bone quality. ${ }^{7}$ Ito et $\mathrm{al}^{8}$ classified the approaches to alter implant surfaces as physicochemical, morphologic, or biochemical.

\section{Physicochemical Methods}

These methods alter the surface energy, surface charge, and surface composition to influence cell and tissue response to implants. The method employed is the glow discharge treatment, in which materials are exposed to ionized inert gas, such as argon. During collisions with substrate, high-energy species "scrub" contaminants from the surface, thereby unsaturating surface bonds and increasing surface energy. This higher surface energy influences cell and tissue behavior by enhancing the adsorption of biomolecules. ${ }^{9}$

\section{Morphological Methods}

These methods alter surface morphology and roughness with the aim of refining the bone-implant interface. Many animal studies support that interfacial and shear strengths are influenced by bone ingrowth into macro rough surfaces. It is noteworthy that surfaces with specially contoured grooves can induce contact guidance, whereby direction of cell movement is affected by morphology of substrate. The added advantage is that this method prevents the epithelial downgrowth on dental implants. ${ }^{10}$

Wennerberg and Albrektsson ${ }^{10}$ have classified implant surfaces based on:

Surface roughness:

- Minimally rough (0.5-1 $\mu \mathrm{m})$

- Intermediately rough (1-2 $\mu \mathrm{m})$

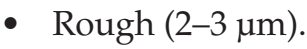


Texture obtained:

- Concave texture (mainly by additive treatments like hydroxyapatite [HA] coating and titanium plasma spraying)

- Convex texture (mainly by subtractive treatment like etching and blasting).

Orientation of surface irregularities:

- Isotropic surfaces: Having the same topography independent of measuring direction

- Anisotropic surfaces: Having clear directionality and differ considerably in roughness. ${ }^{11}$

\section{METHODS TO ENHANCE SURFACE ROUGHNESS}

\section{Mechanical Treatments}

Mechanical treatments involve either removal of surface material by cutting or abrasive action, or the surface of the implant is deformed (and/or partially removed) by particle blasting. ${ }^{12}$ The most commonly employed mechanical techniques are machining, polishing, and blasting. ${ }^{13}$

Machining (lathing, milling, threading) per se is not a surface treatment method, but it can be used to produce specific surface topographies and surface compositions. Machined implant surface is generally characterized by grooves and valleys more or less oriented along the machining direction ${ }^{13}$ and the surface layers are plastically deformed.

Depending on the machining parameters - work-piece speed, tool pressure, and choice of lubricant - surface roughness values ( $\mathrm{Ra}$ - mean arithmetic roughness) may range between 0.3 and $0.6 \mu \mathrm{m}$ when measured by optical or stylus profilometry. ${ }^{14,15}$

Grinding and mechanical polishing are identical methods wherein some of the surface material is removed by using a hard abrasive. ${ }^{13,16}$ Grinding involves use of coarse particles as abrasive medium to remove the surface at a faster rate and creates relatively rough surface topographies.

Depending on the abrasive grade $\mathrm{Ra}$ values ranging from 1 to $6 \mu \mathrm{m}$ can be achieved. ${ }^{16}$

Polishing of the implant surface involves use of a fine abrasive material, i.e., applied to a flexible wheel or a belt and then the implant is brought into direct contact with the abrasive surface. Polishing is always carried out in the presence of lubricant. Polishing is generally carried out using $\mathrm{SiC}$, alumina, or diamond to produce extremely smooth and mirror-like surface with Ra values of $0.1 \mu \mathrm{m}$ or less. ${ }^{12}$

Grit blasting, also known as abrasive blasting, is another technique which is used to create surface topographies on the implant surfaces. In grit blasting, the particles are projected through a nozzle at high velocity by means of compressed air. Various types of ceramic particles, such as alumina, silica, etc., of different sizes can be used for grit blasting of titanium. ${ }^{12,17}$ This technique is generally employed for descaling and surface roughening of commercial implants, thereby increasing the surface area of the implant for better osseointegration.

Shot peening is a modified method of grit blasting and is used primarily for introducing compressive stresses in the material's surface. It is most commonly used for producing specific surface topographies on various biomaterial surfaces. ${ }^{12}$

Depending on the particle size of aluminum, surface roughness can range from 0.5 to $6 \mu \mathrm{m} .^{18}$

\section{Chemical Treatments}

Different chemical treatments, such as solvent cleaning, wet chemical etching, and passivation treatments have been employed for modifying the implant surfaces.

Solvent cleaning is mainly aimed at cleaning the surface of the implant from oils, greases, and fatty surface contaminants remaining after manufacturing process by using organic solvents (aliphatic hydrocarbons, alcohols, ketones, or chlorinated hydrocarbons), surface active detergents, and alkaline cleaning solutions. For effective cleaning, the process may be carried out at elevated temperatures with or without the use of ultrasonication. ${ }^{12}$ This process does not influence implant surface.

Wet chemical etching results in dissolution of the native surface layer of the implant material including the oxide layer and parts of the underlying metal. Chemical etching is also used to improve the surface roughening as well as for producing an esthetically favorable surface finish.

Acid etching or pickling removes oxide layer, thereby providing a clean and uniform surface finish. An aqueous mixture consisting of 10 to 30 volume $\%$ of nitric acid (69 mass \%) and 1 to 3 volume\% of hydrofluoric acid (60 mass $\%)^{12,17,19}$ is the most commonly used etching solution. Degree of pickling/etching is dependent on the acid concentration, temperature, and treatment time (typically in the range of 1-60 minutes). Acid etching preceded by blasting often creates an irregular surface. ${ }^{14,20}$

Surface roughness in the range from $0.1 \mu \mathrm{m}$ to several microns has been reported with this treatment. ${ }^{14,19}$

Alkaline etching is a simple technique to modify the titanium surfaces. Treatment of titanium in 4 to $5 \mathrm{M}$ sodium hydroxide at $600^{\circ} \mathrm{C}$ for 24 hours has been shown to produce sodium titanate gel of $1 \mathrm{~m}$ thick, with an irregular topography with high degree of open porosity. Composition and structure of this layer can be further modified by proper heat treatment. Alternatively, boiling alkali solution $\left(0.2 \mathrm{M}\right.$ sodium hydroxide, $1400^{\circ} \mathrm{C}$ for 
5 hours) can be used to produce a high density of nanoscale pits on the titanium. Surfaces which are etched prior to alkali treatment generally show increased surface porosity. ${ }^{21}$

\section{Electrochemical Treatments}

Electropolishing and anodic oxidation, also known as anodization, are the most commonly employed methods for titanium surface modification. They are based on different chemical reactions occurring at an electrically energized surface (electrode) placed in an electrolyte. The specimen to be treated is made the anode. The parameters that influence surface modification are choice of electrolyte, electrode potential, temperature, current, etc. ${ }^{22}$

In electropolishing technique, a controlled dissolution of the surface takes place under the influence of electrochemical reaction. Choice of the electrolyte is generally a mixture of an acid and alcohols $(60 \mathrm{~mL}$ perchloric acid and $350 \mathrm{mLn}$-butanol, and $540 \mathrm{~mL}$ methanol held at $25^{\circ} \mathrm{C}$ or lower) for titanium. Rate of removal is generally in the range of 1 to $10 \mu \mathrm{m}$ per minute for titanium. Atomic force microscopy reveals that the surfaces are granular in appearance with granule size of few nanometers. ${ }^{23,24}$

Typical surface roughness value $(\mathrm{Ra})$ of electropolished titanium is $<10 \mu \mathrm{m}$.

\section{Vacuum treatments}

Vacuum treatment offers superior control on the processing conditions, especially with respect to cleanliness. Two different types of plasma treatments available are plasma deposition method and plasma surface modification.

Plasma deposition: In plasma deposition, glow discharge is used to deposit the coating material from a separate solid target (sputter deposition) and/or by reactions in the gas phase (reactive sputtering or plasma polymerization).

Plasma surface modification: Surface modification of inorganic materials by cold plasma is achieved by bombardment of energetic ions, leading to removal of atoms and molecules from the surface (sputtering), and reactions between gas or plasma phase and surface atoms. Plasma treatment increases the surface energy of the implant and thereby improves the wetting characteristics as compared with conventional implant surfaces cleaned by using solvents or autoclaving. ${ }^{25,26}$

\section{Plasma-sprayed Hydroxyapatite}

The addition of calcium and phosphorous-based materials as coatings has received significant attention due to the fact that these elements are the same basic components of natural bone, and coatings can be applied along the implant surfaces by various industrial processing methods. ${ }^{27}$ Most commercially available bioceramic coatings are processed as 20 to $50 \mu \mathrm{m}$ thick plasma-sprayed hydroxyapatite (PSHA) coatings. The PSHA coatings mechanically interlock with a grit-blasted or etched metallic surface. ${ }^{28}$ The osseointegration of the dental implant with PSHA is reported to be faster when compared with uncoated implants.

Ion implantation method involves bombardment of implant surface with high-energy ions (approximately $100 \mathrm{KcV}-1 \mathrm{McV}$ range). Ions penetrate the surface of implant to typical depths of approximately 0.1 to $1 \mu \mathrm{m} .{ }^{29}$ Ion implantation is influenced by the concentration of ions and their energy. ${ }^{12}$ It is most commonly used on those surfaces of implants which are subjected to high wear conditions, such as orthopedic devices to increase surface hardness and reduce the generation of wear debris. This process when used on dental implants resulted in an increase in corrosion resistance by forming Ti-N surface. ${ }^{29}$

Further, this technique is also used to produce antimicrobial surfaces on the implants. The two methods used for this purpose are plasma-based ion implantation and plasma-based ion implantation and deposition. It is suggested that ions like $\mathrm{F}$ and $\mathrm{Ag}$ with antibacterial property can be implanted and deposited on the surface of stainless steel implants with no toxic effect. ${ }^{30}$

\section{Sputter Deposition}

Sputtering involves ejection of atoms and molecules when a material surface is bombarded with high-energy ions in a vacuum chamber. A common drawback inherent in all sputter techniques is that the deposition rate is very low and the process itself is very slow. ${ }^{31}$ With the advent of magnetically enhanced variant of diode sputtering, known as radio frequency (RF) magnetron sputtering, the deposition rate has been reported to improve.

\section{Radio Frequency Sputtering}

Radio frequency magnetron sputtering is a very suitable technique to deposit thin films of CaP coatings on titanium implants. With this technique, standardized $\mathrm{CaP}$ coatings are deposited on titanium substrates. The advantage of this technique is that the coating shows strong adhesion to the titanium and the $\mathrm{Ca} / \mathrm{P}$ ratio and crystallinity of the deposited coating can be varied easily. Sputter-coated implants have reported higher boneimplant contact percentages in animals. ${ }^{32,33}$

\section{Magnetron Sputtering}

Magnetron sputtering is a viable thin-film technique as it allows the mechanical properties of titanium to be 
preserved while maintaining the bioactivity of the coated HA. Films are deposited in a custom-built sputter deposition chamber at room temperature. With outward diffusion of titanium into the HA layer, a strong HA titanium bonding is seen, forming $\mathrm{TiO}_{2}$ at the interface. ${ }^{34}$

\section{Sol-Gel Technique}

\section{Nanotitania Coatings}

Nanotitania coatings were prepared during a study by using the sol-gel technique. Commercially available tetraisopropyl orthotitanate was dissolved in absolute ethanol. Ethyleneglycol monoethylether, deionized water, and fuming $\mathrm{HCl} 37 \%$ were dissolved in ethanol. This was followed by rapid mixing and stirring the two solutions for 3 minutes. Consequently, the coating sol was aged for 24 hours at $0^{\circ} \mathrm{C}$ after which dip coating of Ti substrates occurred. The coated substrate was withdrawn at $0.30 \mathrm{~mm} / \mathrm{s}$ and then heat treated at $500^{\circ} \mathrm{C}$ for 10 minutes. Then they were cleaned in acetone in an ultrasonic bath for 5 minutes and dried at ambient temperature. ${ }^{35}$ The Nanotitania implants had an increased feature density and a large feature coverage area as compared with the nano-HA implants. This could present more binding sites for the protein cell attachment and for increased bone contact. The Nanotitania implants exhibited an ordered arrangement, forming a homogenous layer on underlying topography. The nano-HA implants revealed nano-HA features in being placed in a semi-ordered arrangement and not covering the entire surface.

\section{Thermal Treatment}

Commercially pure titanium with crack-free and uniformly rough surface is thermally annealed up to $1000^{\circ} \mathrm{C}$ to form oxide layer composed of anatase and rutile structures of $\mathrm{TiO}_{2}$. The average roughness of the oxidized surface reported when the titanium is annealed at 600 and $650^{\circ} \mathrm{C}$ for 48 hours was 0.90 and $1.30 \mu \mathrm{m}$ respectively, whereas the average roughness of untreated sample was $0.08 \mu \mathrm{m} .{ }^{36}$

\section{Laser Treatment}

Implant surface roughening using the previously discussed methods would cause surface contamination. Laser enables implant surface treatment without direct contact and provides better control on the microtopography of the implant. Laser treatments are rapid, clean, and suitable for selective modification of surfaces. The average surface roughness of the laser-treated acid-etched implant was $2.28 \mu \mathrm{m} .{ }^{35}$ Clinical studies have indicated more bone formation around the laser-treated implants. ${ }^{37,38}$ This observation can be due to the formation of TiN on the surface that improves biocompatibility. ${ }^{39}$

\section{Photofunctionalization}

Ultraviolet light-mediated photofunctionalization of titanium has recently attracted considerable attention as a means to improve osteoconductivity of titanium implants as it restores their superhydrophilicity, reducing surface carbon and optimizing surface electrostatic charges. These biologic and physiochemical features are collectively known as photofunctionalization. ${ }^{39-41}$

\section{Biomimetic Surfaces}

In order to improve and accelerate osseointegration, several attempts have been made to modify surface properties. Of these, some osteogenic drugs have been applied to implant surfaces. Incorporation of bone antiresorptive drugs, such as bisphosphonates, is believed to improve the prognosis of clinical cases lacking bone support.

\section{Bisphosphonates}

Bisphosphonate-loaded implant surfaces have been reported to improve implant osseointegration. Bisphosphonates are antiresorptive agents that have beneficial effects for the patients on preventing further bone loss, and their effect on increasing the bone mass is modest. ${ }^{42,43}$

Simvastatin could induce the expression of bone morphogenetic protein that might promote bone formation. ${ }^{44}$

Simvastatin given per-orally to adult rats has reported to increase cancellous bone mass and cancellous bone compressive strength. ${ }^{45}$

\section{Antibiotic Coating}

Antibacterial coatings on the surface of implants that add antibacterial property to the implants themselves have been studied as a possible way to prevent surgical site infections associated with implants. Tetracycline- $\mathrm{HCl}$ treatment has been regarded as a practical and effective chemical modality for decontamination and detoxification of contaminated implant surface.

Gentamicin in conjunction with the layer of HA coated on the implant surface may act as a local prophylactic agent when used along with the systemic antibiotics in dental implant surgery. ${ }^{46}$

\section{CONCLUSION}

Since the advent of implants into dentistry, many approaches have been employed to improve the boneimplant interface with the aim of quickly establishing and firmly maintaining osseointegration. An appropriately modified titanium surface would certainly be the key factor for achieving fast and stable implant bone connection, although the methods discussed have been 
successfully developed and employed to produce dental implants with varying surface topographies. However, clinical trials comparing different commercially available implant surfaces under similar clinical situations are rarely disclosed, making the outcome assessment between the different surfaces quite difficult. The use of nanotechnology and the release of biologically active substances constitute promising routes for faster and biologically compatible results, but still more clinical studies are certainly needed.

\section{REFERENCES}

1. Brånemark PI, Adell R, Breine $U$, Hansson BO, Lindström J, Ohlsson A. Intra-osseous anchorage of dental prostheses. I. Exp studies. Scand J Plast Reconstr Surg 1969 Jan;3(2): 81-100.

2. Linder L, Albrektsson T, Brånemark PI, Hansson HA, Ivarsson B, Jönsson U, Lundström I. Electron microscopic analysis of the bone-titanium interface. Acta Orthop Scand 1983 Feb;54(1):45-52.

3. Wennerberg A, Albrektsson T. On implant surfaces: a review of current knowledge and opinions. Int J Oral Maxillofac Implants 2010 Jan-Feb;25(1):63-74.

4. Albrektsson T, Sennerby L. Direct bone anchorage of oral implants: clinical and experimental considerations of the concept of osseointegration. Int J Prosthodont 1990 Jan;3(1): 30-41.

5. Cooper LF. Biologic determinants of bone formation for osseointegration: clues for future clinical improvements. J Prosthet Dent 1998 Oct;80(4):439-449.

6. Grassi S, Piattelli A, de Figueiredo LC, Feres M, de Melo L, Iezzi G, Alba RC Jr, Shibli JA. Histologic evaluation of early human bone response to different implant surfaces. J Periodontol 2006 Oct;77(10):1736-1743.

7. Gupta A, Dhanraj M, Sivagami G. Status of surface treatment in endosseous implant: a literary overview. Indian J Dent Res 2010 Jul-Sep;21(3):433-438.

8. Ito Y, Kajihara M, Imanishi Y. Materials for enhancing cell adhesion by immobilization of cell-adhesive peptide. J Biomed Mater Res 1991 Nov;25(11):1325-1337.

9. Puleo DA, Thomas MV. Implant surfaces. Dent Clin North Am 2006 Jul;50(3):323-338, v.

10. Wennerberg A, Albrektsson T. Effects of titanium surface topograpy in bone integration: a systematic review. Clin Oral Impl Res 2009 Jul;(Suppl 4):172-184.

11. Brunette DM. The effects of implant surface topography on the behavior of cells. Int J Oral Maxillofac Implants 1988 Winter;3(4):231-246.

12. Lausmaa, J. Mechanical, thermal, chemical and electrochemical surface treatment of titanium. In: Titanium in medicine. Berlin: Springer; 2001. p. 231-266.

13. Ellingsen JE, Thomsen P, Lyngstadaas SP. Advances in dental implant materials and tissue regeneration. Periodontology 20002006 Jun;41(1):136-156.

14. Buser D, Nydegger T, Oxland T, Cochran DL, Schenk RK, Hirt HP, Snétivy D, Nolte LP. Interface shear strength of titanium implants with a sandblasted and acid-etched surface: a biomechanical study in the maxilla of miniature pigs. J Biomed Mater Res 1999 May;45(2):75-83.
15. Wennerberg A, Albrektsson T, Johansson C, Andersson B. Experimental study of turned and grit-blasted screw-shaped implants with special emphasis on effects of blasting material and surface topography. Biomaterials 1996 Jan;17(1):15-22.

16. Bowers KT, Keller JC, Randolph BA, Wick DG, Michaels CM. Optimization of surface micromorphology for enhanced osteoblast responses in vitro. Int J Oral Maxillofac Implants 1992 Fall;7(3):302-310

17. Kohles SS, Clark MB, Brown CA, Kenealy JN. Direct assessment of profilometric roughness variability from typical implant surface types. Int J Oral Maxillofacial Implants 2004 Jul-Aug;19(4):510-516.

18. Wieland M, Chehroudi B, Textor M, Brunette DM. Use of Ticoated replicas to investigate the effects on fibroblast shape of surfaces with varying roughness and constant chemical composition. J Biomed Mater Res 2002 Jun;60(3):434-444.

19. Sittig C, Textor M, Spencer ND, Wieland M, Vallotton PH. Surface characterization of implant materials c.p. Ti, Ti-6Al$7 \mathrm{Nb}$ and Ti-6Al-4V with different pretreatments. J Mater Sci Mater Med 1999 Jan;10(1):35-46.

20. Mendonça G, Mendonça DB, Aragão FJ, Cooper LF. Advancing dental implant surface technology - from micron- to nanotopography. Biomaterials 2008 Oct;29(28):3822-3835.

21. Wen HB, Liu Q, De Wijn JR, De Groot K, Cui FZ. Preparation of bioactive microporous titanium surface by a new two-step chemical treatment. J Mater Sci Mater Med 1998 Mar;9(3): 121-128.

22. Kim KH, Ramaswamy N. Electrochemical surface modification of titanium in dentistry. Dent Mater J 2009 Jan;28(1):20-36.

23. Larsson C, Thomsen P, Lausmaa J, Rodahl M, Kasemo B, Ericson LE. Bone response to surface modified titanium implants: studies on electropolished implants with different oxide thicknesses and morphology. Biomaterials 1994 Oct;15(13):1062-1074.

24. Larsson C, Thomsen P, Aronsson BO, Rodahl M, Lausmaa J, Kasemo B, Ericson LE. Bone response to surface-modified titanium implants: studies on the early tissue response to machined and electropolished implants with different oxide thicknesses. Biomaterials 1996 Mar;17(6):605-616.

25. Aronsson BO, Lausmaa J, Kasemo B. Glow discharge plasma treatment for surface cleaning and modification of metallic biomaterials. J Biomed Mater Res 1997 Apr;35(1):49-73.

26. Kilpadi DV, Lemons JE. Surface energy characterization of unalloyed titanium implants. J Biomed Mater Res 1994 Dec;28(12):1419-1425.

27. Kirsch A. Plasma-sprayed titanium-I.M.Z. implant. J Oral Implantol 1986;12(3):494-497.

28. Knabe C, Klar F, Fitzner R, Radlanski RJ, Gross U. In vitro investigation of titanium and hydroxyapatite dental implant surfaces using a rat bone marrow stromal cell culture system. Biomaterials 2002 Aug;23(15):3235-3245.

29. Lacefield WR. Materials characteristics of uncoated/ceramiccoated implant materials. Adv Dent Res 1999 Jun;13(1):21-26.

30. Shinonaga $Y$, Arita K. Surface modification of stainless steel by plasma-based fluorine and silver dual ion implantation and deposition. Dent Mater J 2009 Nov;28(6):735-742.

31. Jansen JA, Wolke JG, Swann S, Van der Waerden JP, de Groot K. Application of magnetron sputtering for producing ceramic coatings on implant materials. Clin Oral Implants Res 1993 Mar;4(1):28-34.

32. Vercaigne S, Wolke JG, Naert I, Jansen JA. A histological evaluation of TiO2-gritblasted and Ca-P magnetron sputter coated 
implants placed into the trabecular bone of the goat: part 2 . Clin Oral Implants Res 2000 Aug;11(4):314-324.

33. Vercaigne S, Wolke JG, Naert I, Jansen JA. A mechanical evaluation of TiO2-gritblasted and Ca-P magnetron sputter coated implants placed into the trabecular bone of the goat: part 1 . Clin Oral Implants Res 2000 Aug;11(4):305-313.

34. Wolke JG, Van Dijk K, Schaeken HG, De Groot K, Jansen JA. Study of the surface characteristics of magnetron-sputter calcium phosphate coatings. J Biomed Mater Res 1994 Dec;28(12):1477-1484.

35. Hsu SH, Liu BS, Lin WH, Chiang HC, Huang SC, Cheng SS. Characterization and biocompatibility of a titanium dental implant with a laser irradiated and dual-acid etched surface. Biomed Mater Eng 2007 Jan;17(1):53-68.

36. Gemelli E, Scariot A, Camargo NH. Thermal characterization of commercially pure titanium for dental applications. Mater Res 2007 Sep;10(3):241-246.

37. Faeda RS, Tavares HS, Sartori R, Guastaldi AC, Marcantonio E Jr. Evaluation of titanium implants with surface modification by laser beam: biomechanical study in rabbit tibias. Braz Oral Res 2009 Apr-Jun;23(2):137-143.

38. Marticorena M,CortiG,Olmedo D, GuglielmottiMB, DuhaldeS. Laser surface modification of Ti implants to improve osseointegration. J Phys Conf Ser 2007;59(1):662.

39. Att $\mathrm{W}$, Ogawa T. Biological aging of implant surfaces and their restoration with ultraviolet light treatment: a novel understanding of osseointegration. Int J Oral Maxillofac Implants 2012 Jul-Aug;27(4):753-761.
40. Ueno T, Yamada M, Hori N, Suzuki T, Ogawa T. Effect of ultraviolet photoactivation of titanium on osseointegration in a rat model. Int J Oral Maxillofac Implants 2010 Mar-Apr;25(2): 287-294.

41. Ogawa T. Ultraviolet photofunctionalization of titanium implants. Oral Craniofac Tissue Eng 2012;2(2):151-158.

42. Kwak HB, Kim JY, Kim KJ, Choi MK, Kim JJ, Kim KM, Shin YI, Lee MS, Kim HS, Kim JW, et al. Risedronate directly inhibits osteoclast differentiation and inflammatory bone loss. Biol Pharm Bull 2009 Jul;32(7):1193-1198.

43. Yoshinari M, Oda $\mathrm{Y}$, Inoue T, Matsuzaka K, Shimono M. Bone response to calcium phosphate-coated and bisphosphonate-immobilized titanium implants. Biomaterials 2002 Jul;23(14):2879-2885.

44. Mundy G, Garrett R, Harris S, Chan J, Chen D, Rossini G, Boyce B, Zhao M, Gutierrez G. Stimulation of bone formation in vitro and in rodents by statins. Science 1999 Dec;286(5446): 1946-1949.

45. Oxlund H, Dalstra M, Andreassen TT. Statin given perorally to adult rats increases cancellous bone mass and compressive strength. Calcif Tissue Int 2001 Nov;69(5):299-304.

46. Alt V, Bitschnau A, Osterling J, Sewing A, Meyer C, Kraus R, Meissner SA, Wenisch S, Domann E, Schnettler R. The effects of combined gentamicin-hydroxyapatite coating for cementless joint prostheses on the reduction of infection rates in a rabbit infection prophylaxis model. Biomaterials 2006 Sep;27(26):4627-4634. 